\title{
Physicochemical and Morphological Properties of a Small Granule Legume Starch With Atypical Properties From Wild Mango (Cordyla africana L.) Seeds: A Comparison to Maize, Pea, and Kidney Bean Starch
}

Nomali Ziphorah Ngobese, Obiro Cuthbert Wokadala,* Belinda Du Plessis, Laura Suzanne Da Silva, Alan Hall, Sello Presly Lepule, Mark Penter, Mduduzi Elijah Khulekani Ngcobo, and Hendrik C. Swart

Dr. N. Z. Ngobese, Dr. O. C. Wokadala, M. Penter, Dr. M. E. K. Ngcobo Agricultural Research Council _ Tropical and Subtropical Crops Nelspruit 1200, South Africa

E-mail: wokadalaO@arc.agric.za

B. D. Plessis, L. S. Da Silva

Department of Biotechnology and Food Technology

Tshwane University of Technology

Arcadia, Pretoria 0001, South Africa

\section{A. Hall}

Laboratory of Microscopy and Microanalysis

University of Pretoria

Hatfield 0028, South Africa

S. P. Lepule

Department of Chemistry

Tshwane University of Technology

Arcadia, Pretoria 0001, South Africa

Prof. H. C. Swart

Department of Physics

University of the Free State

Bloemfontein 9300, South Africa

\begin{abstract}
The physicochemical properties of wild mango (Cordyla africana $\mathrm{L}$ ) seed starch are assessed and compared to bean, pea, and commercial maize starch. Scanning electron microscopy (SEM) and polarized optical microscopy (POM) show that wild mango starch granules are truncated (cap-shaped) have smooth surfaces, and are much smaller $(5.7 \mu \mathrm{m})$ than bean $(28.2 \mu \mathrm{m})$, pea $(23.0 \mu \mathrm{m})$, and maize $(11.1 \mu \mathrm{m})$ starch granules. Wild mango starch had a higher $(p \leq 0.05)$ gelatinization temperature (differential scanning calorimetry-DSC, $\left.T_{p}=77^{\circ} \mathrm{C}\right)$, but a lower enthalpy $\left(\Delta H=10.7 \mathrm{~J} \mathrm{~g}^{-1}\right)$ than pea, bean, and maize starches. X-ray diffraction (XRD) reveals a C-type crystalline pattern, while Fourier transform infrared spectroscopy (FTIR) indicates that the starch has a higher degree of short-range order compared to bean, pea, and maize starches. Rapid visco analysis (RVA) shows that its peak paste viscosity (2811 cP) is significantly ( $p \leq 0.05)$ higher than that of bean, pea, and maize starch. Wild mango starch is similar $(p>0.05)$ to maize starch in terms of RVA granulebreakdown and gelation-related parameters, and gel texture (firmness $=114.7 \mathrm{~N}$ and strength $=339.4 \pm 16.5 \mathrm{~J})$, differed significantly $(p \leq 0.05)$ from bean and pea starch.
\end{abstract}

Keywords: gel textures, gelatinization, legume starches, Rapid Visco-Analysis (RVA), 


\section{Introduction}

Wild mango (Cordyla africana L.) is an underutilized leguminous fruit tree species native to southern Africa. ${ }^{1,2}$ The fruits have a high vitamin $C$ content and are consumed fresh or cooked, ${ }^{1}$ while the seeds that make up close to $40 \% \mathrm{w} / \mathrm{w}$ of the whole fruit weight are discarded. These seeds could be assessed and commercially exploited as a source of valuable ingredients.

There is a growing interest for researchers to find non-conventional sources of starch for the food processing and other industries. ${ }^{3,4}$ Starch is the main source of carbohydrates in the human diet, being the main component in flour and is often used as an additive ingredient in food products such as soups, custard, and sauces. ${ }^{5}$ The demand for starch is increasing rapidly as a wide-range of applications are developed. Finding alternative sources to maize, wheat, and potato may offer additional alternatives for meeting the rising demand in the starch industry.

The selection of starch for specific uses is based on its physico-chemical properties. This is affected by, among other factors: the botanical source of the starch, its amylose/amylopectin ratio, granule structure or size, amylopectin molecular structure/architecture, and the protein and lipid contents. ${ }^{5-7}$ These properties regulate the degree of interaction with water and the changes that occur during heat-moisture treatment. The pasting and gelatinization properties of starch are two of its most important functional properties. These processes involve the disruption of the crystalline structure in amylopectin, promoting the degree of interaction with water and granule swelling. ${ }^{8}$

Legume starch tends to have better gel properties, and resistant starch contents than cereal and tuber starches. ${ }^{9-12}$ The present research aims to characterize the physico-chemical properties of starch from wild mango seeds. This is the first report on the characteristics of wild mango seed starch. The information on the physico-chemical characteristics of wild mango starch will facilitate utilization of the starch.

\section{Experimental Section}

\subsection{Wild Mango Seed Starch Extraction}

Freshly dropped ripe wild mango fruits were collected from a population of trees at the Agricultural Research Council, in Mpumalanga, South Africa $\left(25.4518^{\circ} \mathrm{S}, 30.9697^{\circ} \mathrm{E}\right)$. The fruits were pulped to obtain the seeds, which were dried at $45-50^{\circ} \mathrm{C}$ in a forced convection dryer (AD3000 Agri-Dryer, Dryers for Africa, SA) for 5 days and then stored in heat-sealed plastic bags at $4-10^{\circ} \mathrm{C}$. The seed hulls were removed and the seeds were milled in a laboratory scale rotor beater mill (SR 300, Retsch, Germany) fitted with a $500 \mu \mathrm{m}$ mesh. In order to extract the starch, the flour was mixed with deionised water (volume ratio 1:5) for $2 \mathrm{~h}$, with vigorous stirring, and then sieved through a $360 \mu \mathrm{m}$ mesh sieve. The filtrate was then centrifuged at $5000 \times \mathrm{g}$ for $5 \mathrm{~min}$ at $4{ }^{\circ} \mathrm{C}$. The resultant pellet was re-suspended in deionised water, filtered through a $106 \mu \mathrm{m}$ sieve and washed several times until the 
supernatant was clear. The starch was then collected and dried in a forced convection oven at $40{ }^{\circ} \mathrm{C}$ for $12 \mathrm{~h}$ to obtain starch powder. Starch was also extracted from red speckled kidney beans (Phaseolus vulgaris L.) (Pride, South Africa, product code: 6001001394925) and yellow smooth peas (Pisum sativum) (Shoprite Brand, South Africa, product code: 6002310006486) using the same method, for comparison. The starch yield was estimated as the percent weight of the extracted starch to initial flour weight on a dry weight basis (dwb). Commercial maize starch (Tongaat Hulett, South Africa, product code: 100032) was also obtained for utilization as a reference material for the other sample determinations.

\subsection{Starch Purity and Amylose/Amylopectin Ratio}

The protein, lipid, and phosphorus contents were assessed to gauge the purity of the extracted starch. Briefly, the protein content was determined using an automated Dumas dry combustion method (LECO CNS 2000 Elemental Analyzer [LECO Corporation, USA]) with a conversion factor of 6.25 (AOAC Method $992.23^{13}$ ). Lipid content was determined using the Soxhlet method (AOAC Method 920.3914) through a Soxhlet extraction unit (SER 148 Series, Velp Scientifica, Italy) with petroleum ether. The amylose/amylopectin ratio was determined colorimetrically according to Ngobese et al. ${ }^{15} \mathrm{~A}$ standard curve was prepared using high amylose starch (70\% amylose; Megazyme, Ireland) and waxy maize $(0.05 \%$ amylose; Tongaat Hulett, South Africa). Data were expressed as a percentage on dry weight basis.

\subsection{Starch Granule Morphology and Size Distribution}

Scanning electron and polarized optical microscopy were utilized to determine the granule morphology and size distribution. The starch powder samples (wild mango, bean, pea, and maize) were mounted on scanning electron microscope (SEM) stubs with double-sided adhesive tape and carbon-coated. Micrographs were taken at $1000 \times$ and $5000 \times$ magnification with a with Zeiss Ultra-55 field emission SEM at an acceleration voltage of $5 \mathrm{kV}$. The size (Feret's diameter) of 1255 randomly selected granules (from 15 to 30 micrographs) was measured using ImageJ software (US National Institutes of Health; Bethesda, Maryland, USA). A polarized optical microscope (Zeiss Axio Imager M2, Germany) was used to check for starch damage (maltese test ${ }^{16}$ ) at $40 \mathrm{X}$ magnification on slides prepared with the starch powder in distilled water.

\subsection{Pasting Properties}

The pasting properties of starch were determined according to Kongolo et al. ${ }^{17}$ using a Rapid Visco Analyzer (4500) (Perten Instruments, Sweden). The starch was defatted using hexane prior to the experiments (starch/hexane ratio of 1:10 for $6 \mathrm{~h}$ with slow stirring at room temperature $\left(25^{\circ} \mathrm{C}\right)$. The starch was then mixed with distilled water $(6 \% \mathrm{w} / \mathrm{w} \mathrm{dwb})$. The mixture was equilibrated at $50{ }^{\circ} \mathrm{C}$ for $1 \mathrm{~min}$ and stirred at $960 \mathrm{rpm}$ for $30 \mathrm{~s}$. The stirring speed was reduced to $160 \mathrm{rpm}$ and the temperature was increased to $95^{\circ} \mathrm{C}$ at a rate of $11.08^{\circ} \mathrm{C} \mathrm{min}-1$. The sample was then held at $95^{\circ} \mathrm{C}$ for $150 \mathrm{~s}$. The temperature was reduced $\left(11.08{ }^{\circ} \mathrm{C} \mathrm{min}-1\right)$ to $50{ }^{\circ} \mathrm{C}$ and held for $60 \mathrm{~s}$. For each sample, ${ }^{3}$ replicate experiments were done. The peak time and viscosity, final viscosity, setback viscosity, and pasting temperature were determined. 


\subsection{Gel Texture}

The starch cold gel texture was assessed according to Kongolo et al. ${ }^{17}$ using a TA.XT Plus Texture Analyzer (Stable Micro Systems, UK) fitted with a $2 \mathrm{~mm}$ diameter cylinder probe. The pastes obtained from the RVA were transferred to a plastic container $(3.5 \mathrm{~cm}$ diameter, $1.1 \mathrm{~cm}$ height) and allowed to stand for $2 \mathrm{~h}$ at room temperature $\left(25^{\circ} \mathrm{C}\right)$. The gel texture was then analyzed using the following parameters: pre-test and test speed $\left(1 \mathrm{~mm} \mathrm{~s}^{-1}\right)$, posttest speed $\left(10 \mathrm{~mm} \mathrm{~s}^{-1}\right)$, and penetration distance $(5 \mathrm{~mm})$. For each sample, six replicate tests were done. Gel firmness (maximum penetration force) and gel strength (positive area under the force-time curve) were obtained with the TA.XT Exponent(C) software.

\subsection{Thermal Properties}

Thermal properties of the starch were analyzed using a differential scanning calorimeter (DSC) (HPDSC-827, Mettler Toledo, Switzerland]) equipped with STARe 127 software according to Kongolo et al. ${ }^{17} \mathrm{~A}$ suspension of starch and distilled water $(1: 3 \mathrm{w} / \mathrm{w})$ was placed in a DSC aluminum pan and hermetically sealed with a lid. The mixture was left to equilibrate for at least $2 \mathrm{~h}$ at room temperature $\left(25^{\circ} \mathrm{C}\right)$. The mixture was then heated from 35 to $100{ }^{\circ} \mathrm{C}$, at a scanning rate of $10^{\circ} \mathrm{C} \mathrm{min}^{-1}$. An empty DSC pan was used as a reference and indium was used for calibration. The experiments were done under nitrogen with a flow rate of $40 \mathrm{~mL} \mathrm{~min}^{-1}$ at atmospheric pressure. The experiments were done in duplicate. The gelatinization onset temperature $\left(T_{o}\right)$, peak temperature $\left(T_{p}\right)$, end temperature $\left(T_{c}\right)$, and enthalpy $(\Delta H)$ were recorded.

\subsection{X-Ray Diffraction}

The crystalline structure of the wild mango, pea, bean, and maize starches was determined using an Advanced D8 Bruker powder X-ray diffractometer (Brucker, Kalsruhe, Germany). The experiments were run at voltage $40 \mathrm{kV}$ and with current of $40 \mathrm{~mA}$. The $\mathrm{X}$-ray diffraction was recorded from 2 to $40^{\circ} 2 \theta$ at a scanning speed of $2^{\circ} \mathrm{min}^{-1}$ and a step interval of 0.05 .

\subsection{Fourier Transform Infrared (FTIR) Spectrometry}

FTIR of the starches was performed using a Perkin Elmer 2000 FTIR spectrometer with Spectra $10^{\mathrm{TM}}$ software (Perkin-Elmer, Norwalk, USA) at room temperature $\left(25^{\circ} \mathrm{C}\right)$. The absorbance spectra were recorded in the wavenumber range of $4000-700 \mathrm{~cm}^{-1}$. Thirty-two scans were accumulated for each spectrum/run at a resolution of $4 \mathrm{~cm}^{-1}$ and the starch samples were analyzed in triplicate. The spectra obtained were baseline corrected, normalized, and deconvoluted to enable comparison of samples. The short-range crystallinity was determined as the peak height ratio $1045 / 1022 \mathrm{~cm}^{-1} .{ }^{18}$

\subsection{Statistical Analysis}

Statistical analyses were done using Genstat version 18 (VSN International, United Kingdom). Statistical significance was determined using a one-way analysis of variance (ANOVA) and data were reported as mean \pm standard deviation, where applicable. Mean 
comparison and separation was done using the Bonferroni's multiple comparison test with a 95\% confidence interval $(p \leq 0.05)$.

\section{Results and Discussion}

\subsection{Starch Purity and Amylose/Amylopectin Ratio}

The purity of the starch was evaluated by assessing the protein, and free lipids contents and through bright field microscopy to check for visible impurities. The free lipids and protein contents of the wild mango starch were within the range of values of the bean, pea and maize starches used as controls in the present study (Table 1). The values were considered negligible because they were relatively low. The starch yield from the wild mango, bean, and pea flours was $18.9,22.0$, and $35.0 \% \mathrm{w} / \mathrm{w}$ dwb of flour. These values were within the range of values typically reported for legumes. ${ }^{19}$

Table 1. Protein, free lipids, and amylose contents of wild mango starch compared to bean, pea, and maize starch

\begin{tabular}{lrrr}
\multicolumn{1}{l}{ Starch source } & \multicolumn{1}{c}{ Protein $[\% \mathbf{w} / \mathbf{w}]$} & Lipids $[\% \mathbf{w} / \mathbf{w}]$ & Amylose $[\% \mathbf{w} / \mathbf{w}]$ \\
Wild mango & $0.64 \pm 0.07^{\mathrm{b}}$ & $0.21 \pm 0.06^{\mathrm{b}}$ & $25.5 \pm 0.3^{\mathrm{a}}$ \\
Bean & $0.46 \pm 0.02^{\mathrm{a}}$ & $1.14 \pm 0.08^{\mathrm{d}}$ & $30.9 \pm 1.3^{\mathrm{b}}$ \\
Pea & $0.85 \pm 0.01^{\mathrm{c}}$ & $0.05 \pm 0.07^{\mathrm{a}}$ & $31.7 \pm 0.5^{\mathrm{b}}$ \\
Maize & $0.44 \pm 0.04^{\mathrm{a}}$ & $0.91 \pm 0.08^{\mathrm{c}}$ & $24.4 \pm 1.1^{\mathrm{a}}$
\end{tabular}

\footnotetext{
Values indicate mean of triplicate analyses \pm standard deviation. Values with the same letters in a column are not significantly different. Values are reported on dry mass basis (dwb) of extracted starch.
}

The amylose content of wild mango starch $(25.5 \pm 0.2 \% \mathrm{w} / \mathrm{w}$ dwb of starch) was not significantly different from that of maize starch $(24.4 \pm 1.0 \% \mathrm{w} / \mathrm{w} \mathrm{dwb})$, but was significantly $(p \leq 0.05)$ lower than that of bean $(30.9 \pm 1.3 \% \mathrm{w} / \mathrm{w} \mathrm{dwb})$ and pea $(31.7 \pm 0.5 \% \mathrm{w} / \mathrm{w} \mathrm{dwb})$ starches. The amylose content of the wild mango seed starch was within the range (19.5$34.0 \%$ ) reported for acorn starch. ${ }^{20}$ The amylose contents of bean, pea, and maize starches reported in the present study were consistent with those reported in the literature for maize, pea, and bean starches. ${ }^{19,}{ }^{21}$ The lower amylose content in wild mango starch compared to the bean and pea starches was unexpected given legumes usually have high amylose contents. ${ }^{9-12,} 22$ The similarity in amylose content of the wild mango starch to conventional starches (maize, pea, bean), implies that its digestibility may not be particularly different given digestibility is related to the amylose content.

\subsection{Starch Granule Morphology and Size Distribution}

Figure 1 shows the SEM micrographs of wild mango starch compared to bean, pea, and maize starches. Wild mango starch consisted of truncated/cap-shaped, smooth-surfaced granules (Figure 1a). These granules were clearly different from those of bean and pea 
(round to oval-shaped), and maize (polygonal). Wild mango granules resembled those of cassava, ${ }^{23,} 24$ jackfruit, ${ }^{25-27}$ tannia, ${ }^{28}$ and sago, ${ }^{29}$ which are cap-shaped/truncated. Polarized optical microscopy revealed a strong birefringence pattern in wild mango starch granules (Figure 1a, bottom right), which indicated structural integrity of the amylopectin helices and suggests that the truncation of the granules is not a result of starch damage. ${ }^{10}$

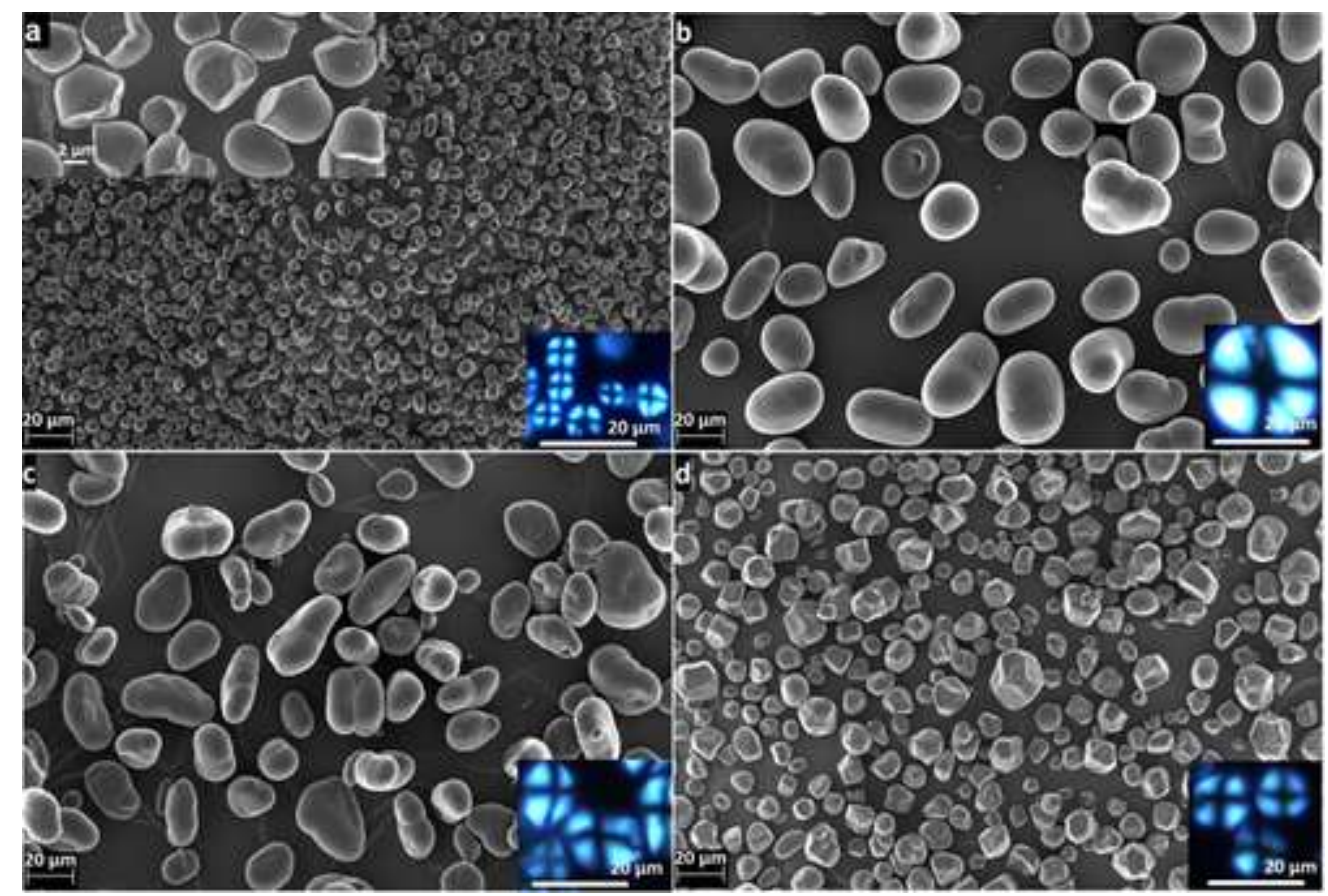

Figure 1 Scanning electron microscopy (SEM) images of wild mango a), bean b), pea c), and maize d) starches. Images in the bottom-right corner of each diagram are from polarized light microscopy (POM). The image in the top-left corner of (a), is a $5000 \times$ magnification image of wild mango granules.

Wild mango granules had a mean size (Feret's diameter) of $5.7 \mu \mathrm{m}$ and were clearly smaller than those of bean $(28.2 \mu \mathrm{m})$, pea $(23.0 \mu \mathrm{m})$, and maize starch $(11.1 \mu \mathrm{m})$ (Figure 1). The wild mango starch granules were also smaller than similarly shaped granules reported in literature, such as cassava $(15 \mu \mathrm{m}),{ }^{23,24}$ jackfruit $(7.6 \mu \mathrm{m}),{ }^{25-27}$ tannia $(14.7 \mu \mathrm{m}),{ }^{28}$ and sago $(30 \mu \mathrm{m})^{29}$ starch granules. The wild mango seed starch granules were also smaller than those reported for acorn starch $(10.2-43.3 \mu \mathrm{m}) .{ }^{20}$ The wild mango starch granule size showed a normal/unimodal distribution with a narrower distribution than bean, pea, and maize starches (Figure 2). Most wild mango starch granules were between 3 and $10 \mu \mathrm{m}$ in diameter (Figure 2). The homogeneity and size of these granules indicates potential for producing a creamy mouth feel in food products. Small-sized starch granules are considered favorable fat replacers for the reduction of the fat content in desserts. ${ }^{30}$ 


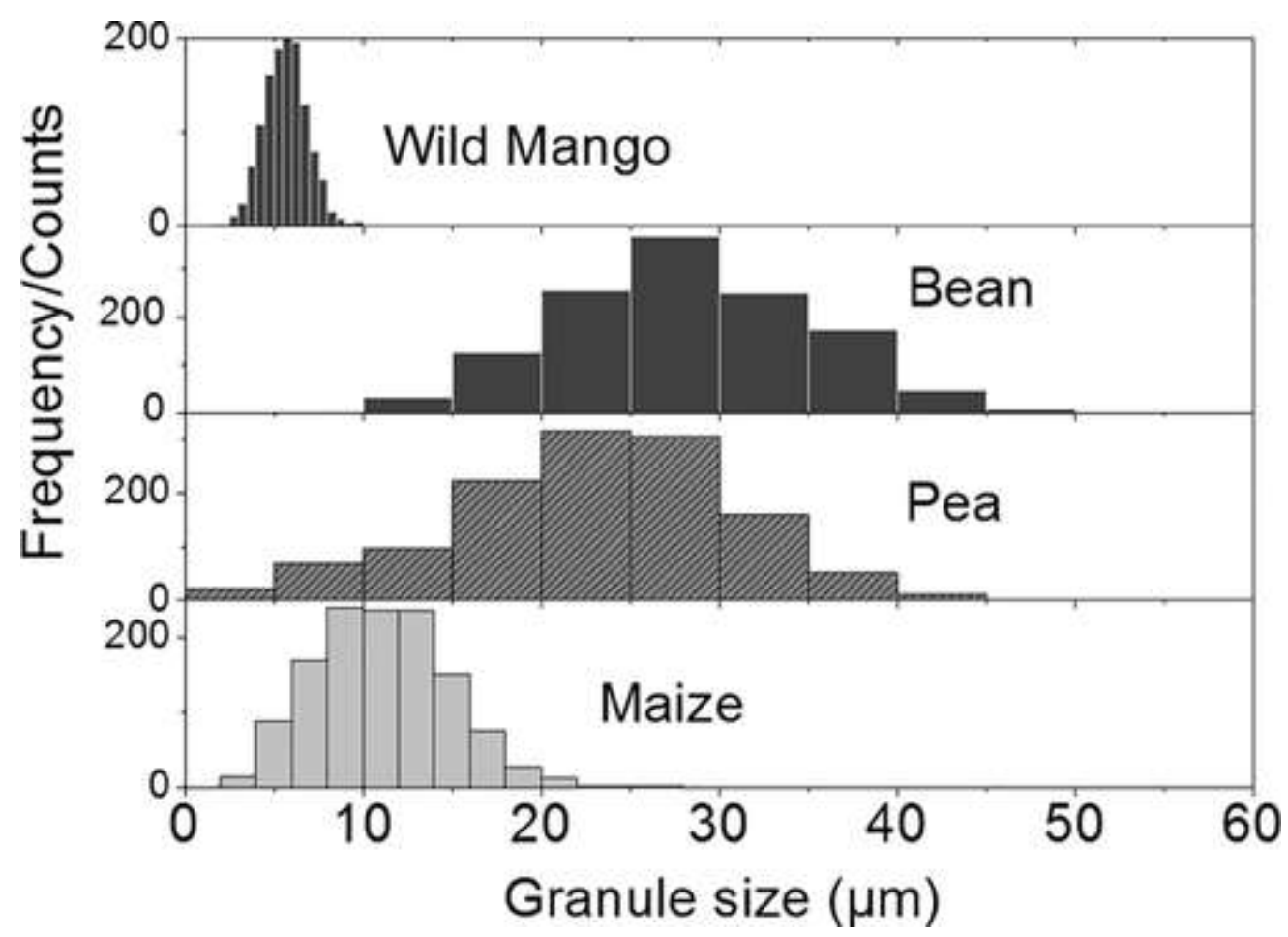

Figure 2 Granule size distribution of wild mango starch compared to bean, pea, and maize starches. Plotted values were obtained from measuring the Feret's diameter of 1255 granules in from 15-30 SEM micrographs.

\subsection{Pasting Properties (Rapid Visco-Analysis)}

Wild mango had a significantly $(p \leq 0.05)$ higher peak paste, and final viscosity than bean, pea, and maize starch (Table 2). This implied that lower quantities of wild mango starch could be added to food products to attain the same hot paste viscosity as pea, bean, and maize starches. The wild mango starch trough, breakdown, and setback viscosities plus the pasting temperature were not significantly $(p>0.05)$ different from maize (Table 2$)$.

However, they were significantly $(p \leq 0.05)$ different from those of bean and pea starches (Table 2). These results indicated that the resistance to granule breakdown due to shear during heat-moisture treatment and rate of gelling during cooling, for wild mango starch, was identical to cereal starch (maize) rather than to legume starch (bean and pea). The similarities to maize starch were probably associated to the similarities in amylose content in these two starches. ${ }^{31}$ Furthermore, they could indicate a closer similarity at molecular level, which has to be ascertained. The wild mango starch pasting properties hence suggest that it could be a suitable substitute for maize starch rather than for legume starches (bean and pea) in applications that involve heat-moisture treatment. 
Table 2. Pasting properties of wild mango starch compared to bean, pea, and maize starch

$\begin{array}{lcccccc}\begin{array}{l}\text { Starch } \\ \text { source }\end{array} & \begin{array}{c}\text { Peak } \\ \text { viscosity [cP] }\end{array} & \begin{array}{c}\text { Final viscosity } \\ {[\mathrm{cP}]}\end{array} & \begin{array}{c}\text { Trough } \\ \text { viscosity }[\mathrm{cP}]\end{array} & \begin{array}{c}\text { Breakdown } \\ \text { viscosity [CP] }\end{array} & \begin{array}{c}\text { Setback } \\ \text { viscosity [cP] }\end{array} & \begin{array}{c}\text { Pasting } \\ \text { temperature }\left[{ }^{\circ} \mathrm{C}\right]\end{array} \\ \begin{array}{l}\text { Wild } \\ \text { mango }\end{array} & 2811 \pm 32^{\mathrm{c}} & 3336 \pm 42^{\mathrm{b}} & 1609 \pm 81^{\mathrm{a}} & 1202 \pm 112^{\mathrm{b}} & 1727 \pm 123^{\mathrm{a}} & 80 \pm 0.6^{\mathrm{c}} \\ \begin{array}{l}\text { Bean } \\ \text { Pea }\end{array} & 2245 \pm 41^{\mathrm{a}} & 4334 \pm 7^{\mathrm{c}} & 1588 \pm 205^{\mathrm{a}} & 657 \pm 164^{\mathrm{a}} & 2746 \pm 212^{\mathrm{b}} & 76 \pm 0.6^{\mathrm{b}} \\ \text { Maize } & 2583 \pm 58^{\mathrm{b}} & 2799 \pm 82^{\mathrm{a}} & 1685 \pm 28^{\mathrm{a}} & 899 \pm 30^{\mathrm{ab}} & 1115 \pm 54^{\mathrm{a}} & 79 \pm 0.0^{\mathrm{c}}\end{array}$

Values indicate mean of triplicate analyses \pm standard deviation.

Values with the same letters in a column are not significantly different.

\subsection{Gel Texture}

The cold gel textural properties of wild mango, bean, pea, and maize starch are shown in Figure 3. Wild mango starch formed a less firm and weaker gel compared to the other legume starches (bean and pea) (Figure 3). The firmness and gel strength of wild mango starch $(114.7 \pm 3.3 \mathrm{~N}$ and $339.4 \pm 16.5 \mathrm{~J}$, respectively) were significantly ( $p \leq 0.05)$ higher than those of maize starch $(82.0 \pm 2.0 \mathrm{~N}$ and $269.0 \pm 7.6 \mathrm{~J}$, respectively). The wild mango gel firmness and strength were however, significantly $(p \leq 0.05)$ lower than those of bean $(296.0 \pm 10.9 \mathrm{~N}$ and $791.9 \pm 33.7 \mathrm{~J}$, respectively) and pea $(253.8 \pm 24.8 \mathrm{~N}$ and $816.0 \pm 54.6 \mathrm{~J}$, respectively) starch (Figure 3). The relative closeness of the gel texture values of the wild mango starch to maize starch (which is the most commercially used starch), rather than to bean and pea starches, implied that the starch could be a more suitable substitute for maize starch in food products that use native maize starch for texture enhancement. In addition, given the significantly higher gel firmness and strength compared to maize starch, lower quantities of the wild mango starch would be required to achieve similar functionality. 


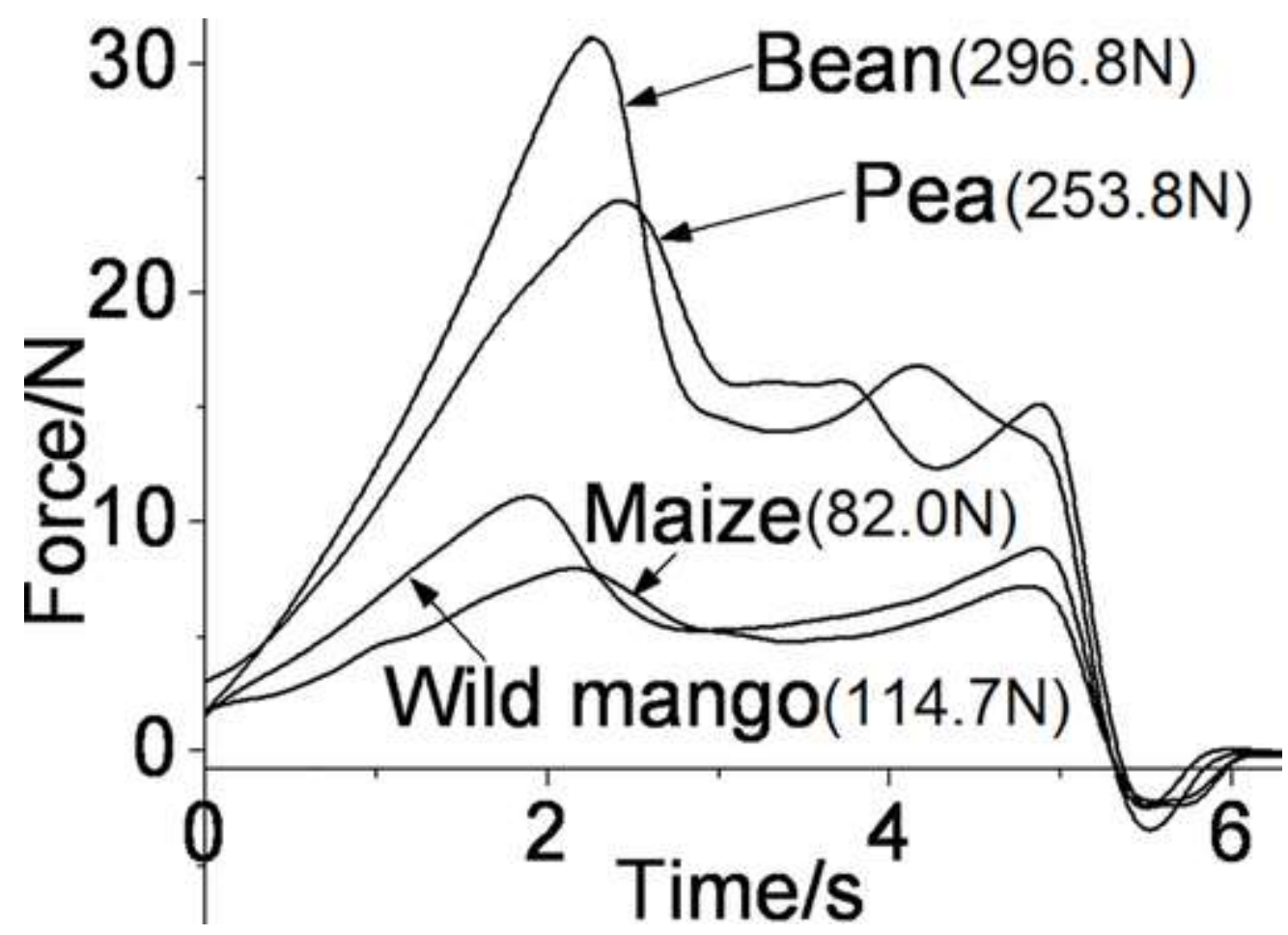

Figure 3 Cold gel texture properties of wild mango starch compared to bean, pea, and maize starches. Plots are representative of six replicate measurements.

Legume starches produce relatively firmer gels compared to other common starches (wheat, maize, and potato). ${ }^{32}$ In the present study, the weaker gel firmness and strength of wild mango starch compared to the other legume starches (bean and pea) corroborates with the final viscosity observed during pasting (Table 2). The weaker gel firmness and strength could be attributed to the relatively lower amylose content (Table 1). Lower amylose contents lead to the formation of a weaker gel due to the formation of fewer junction zone areas in the gel compared to higher amylose starches. Starch with a high amylose content has been shown to have a firmer and more ordered gel structure. ${ }^{33}$

\subsection{Thermal Properties}

The thermal properties of wild mango, bean, pea, and maize starches are shown in Figure 4. Wild mango starch showed significantly $(p \leq 0.05)$ higher gelatinization temperatures $\left(T_{o}, T_{p}\right.$, $T_{c}$ ) as compared to the other starches during gelatinization. The gelatinization peak temperature of wild mango starch was $77.3 \pm 0.1^{\circ} \mathrm{C}$, while that of bean, pea, and maize starches was $69.1 \pm 0.6,68.8 \pm 0.0$, and $73.1 \pm 1.0^{\circ} \mathrm{C}$, respectively. This indicated a higher thermal energy requirement to initiate the disruption of amylopectin crystallites in wild mango starch compared to bean, pea, and maize starch. The enthalpy (total energy consumed to melt all crystallites), of wild mango starch was significantly ( $p \leq 0.05)$ lower than that of bean and pea starches, but was not significantly $(p>0.05)$ different from maize starch. The lower gelatinization enthalpy compared to other legumes, could be an indication of a higher degree of amylopectin branching, given the fact that the abundance of short amylopectin chains leads to lower gelatinization enthalpies. ${ }^{31,34}$ 


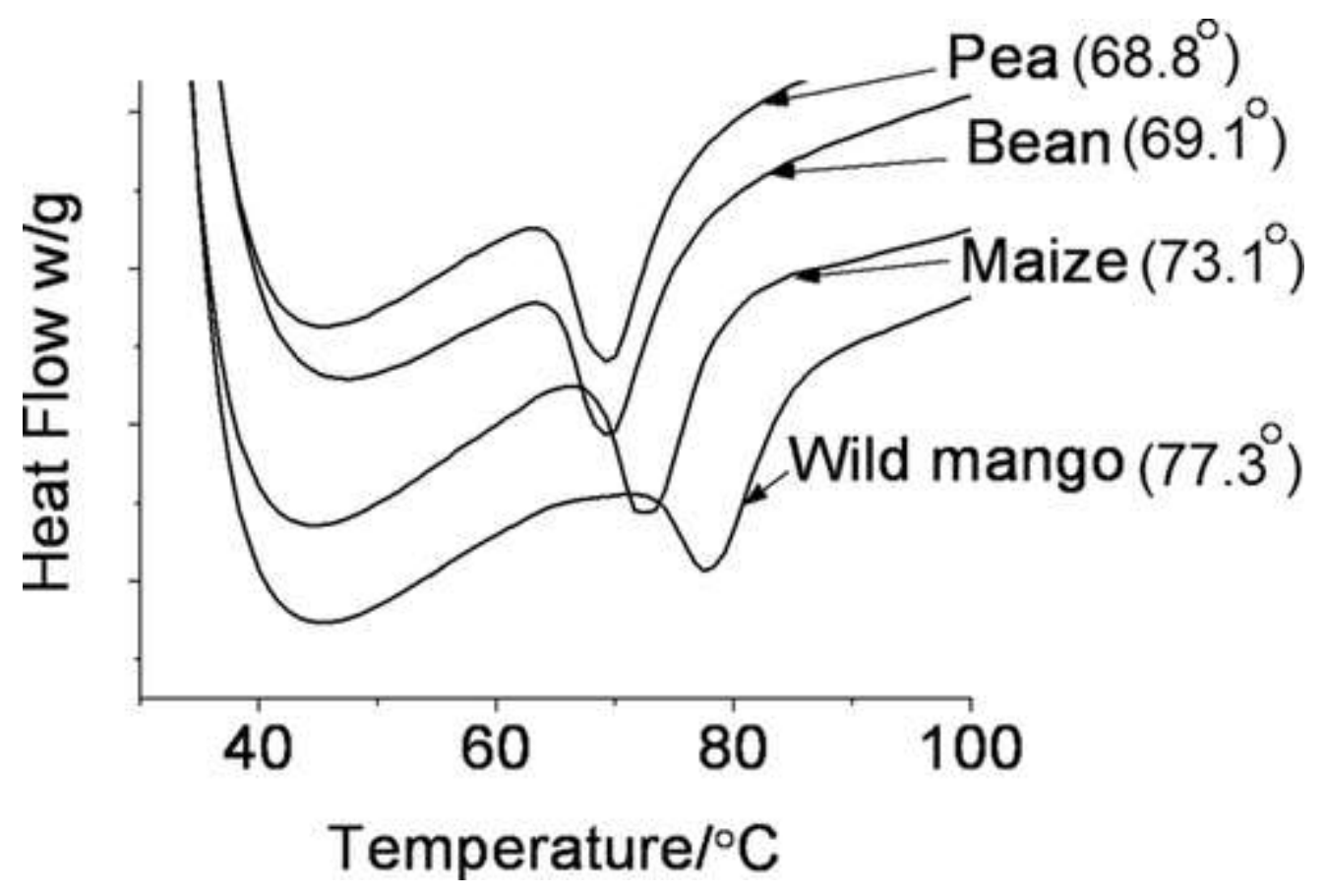

Figure 4 Thermal properties of wild mango starch compared to bean, pea, and maize starches. Plots are representative of duplicate measurements.

\subsection{X-Ray Diffraction}

Figure 5 shows the $X$-ray diffractograms of wild mango, bean, pea, and maize starches. The diffraction pattern is an indication of the crystalline amylopectin unit structure of starch. Wild mango starch exhibited a similar diffraction pattern to that of bean and pea starches, which were different from that of maize starch (Figure 5). Wild mango, bean, and pea starch diffractograms had major peaks around 15.0, 17.1, and $23.1^{\circ} 2 \theta$, which are typical of C-type crystalline structure. ${ }^{35}$ Maize starch exhibited an A-type diffraction pattern that is typical of cereal starches and displays strong diffraction peaks at around 15.0,17.2,18.0,20.0, and $23.1^{\circ} 2 \theta$ regions. ${ }^{21,35} \mathrm{~A}$ C-type diffraction pattern is a mixture of both $\mathrm{A}$ - and $\mathrm{B}$-types, and is usually exhibited in native legume seed starches. Wild mango starch showed a relatively more prominent shoulder at $18.0^{\circ}$ compared to the other legume starches (dotted arrow in Figure 5). The associated peak was most prominent in maize starch (Figure 5). This suggested that structurally, wild mango starch crystallites resemble A-type crystallites (maize). The intra-crystallite bond distances of wild mango seed starch were probably intermediate between cereal and legume starches. In addition, this probably explains why most of the wild mango starch properties were similar to those of maize starch rather than bean and pea starch. 


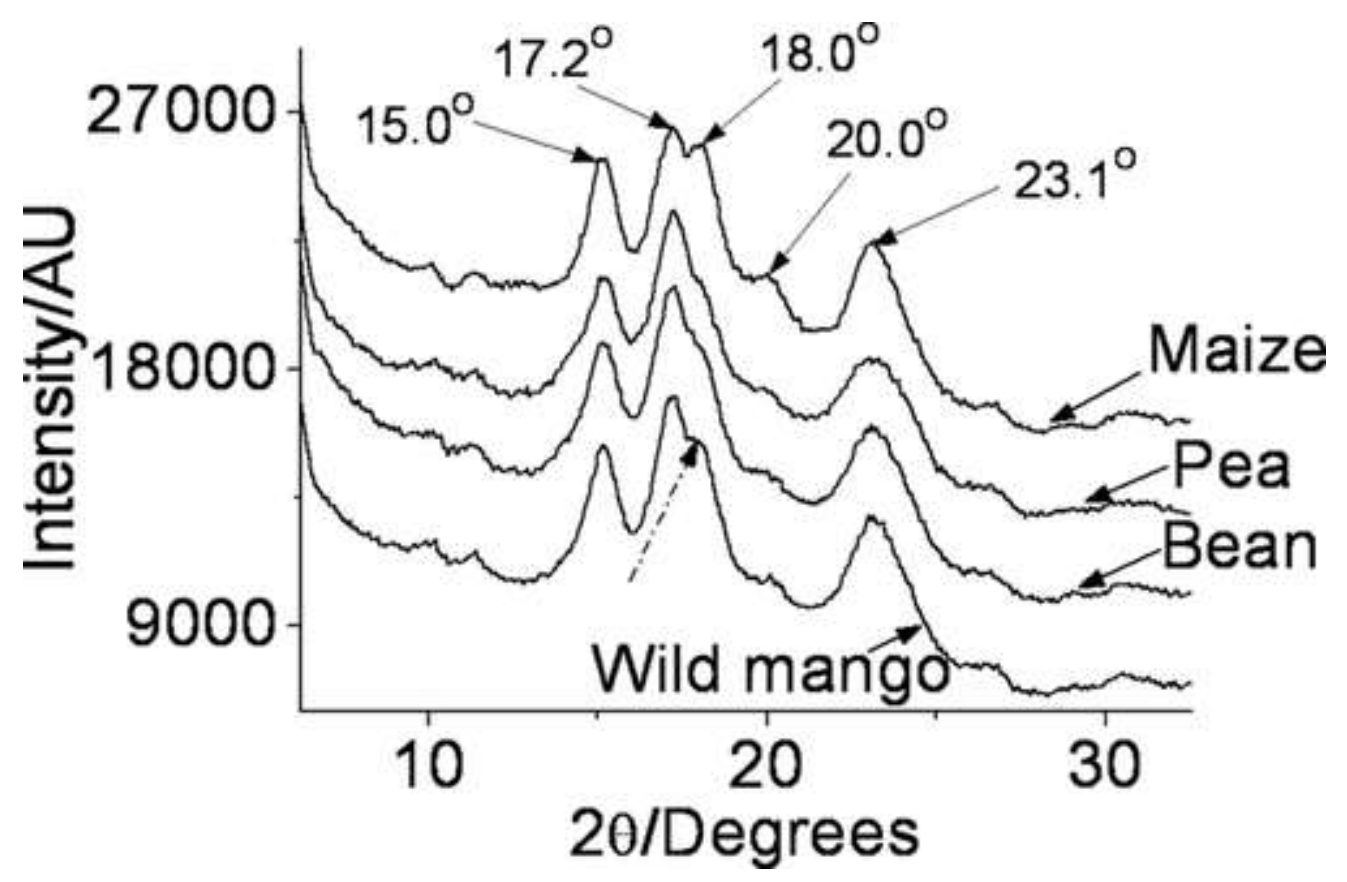

Figure 5 X-ray diffractograms of wild mango starch compared to bean, pea, and maize starches.

\subsection{FTIR Spectroscopy}

Figure 6 shows the $1300-800 \mathrm{~cm}^{-1}$ region of the FTIR spectra obtained from the starches analyzed in the present study. This region has been shown to give the most characteristic information about the structure of starches. ${ }^{36}$ Four characteristic peaks were observed in this fingerprint region and these were attributed to $\mathrm{C}$ ? $\mathrm{O}$ bond stretching, which occurs in the pyranose form of glucose residues. These were at 1150, 1076, 1014, and $997 \mathrm{~cm}^{-1}$ (Figure 6). Wild mango starch had the greater overall absorption intensity compared to the other samples. The observed spectra intensity differences in this starch could be attributed to the differences in granule size (Figure 2). The smaller granule size of wild mango starch, led to more granules per unit volume, hence greater overall IR absorption compared to the other samples. The difference in overall absorption was however minimized by the fact that all the spectra were baseline corrected before normalization and deconvolution (Figure 6). 


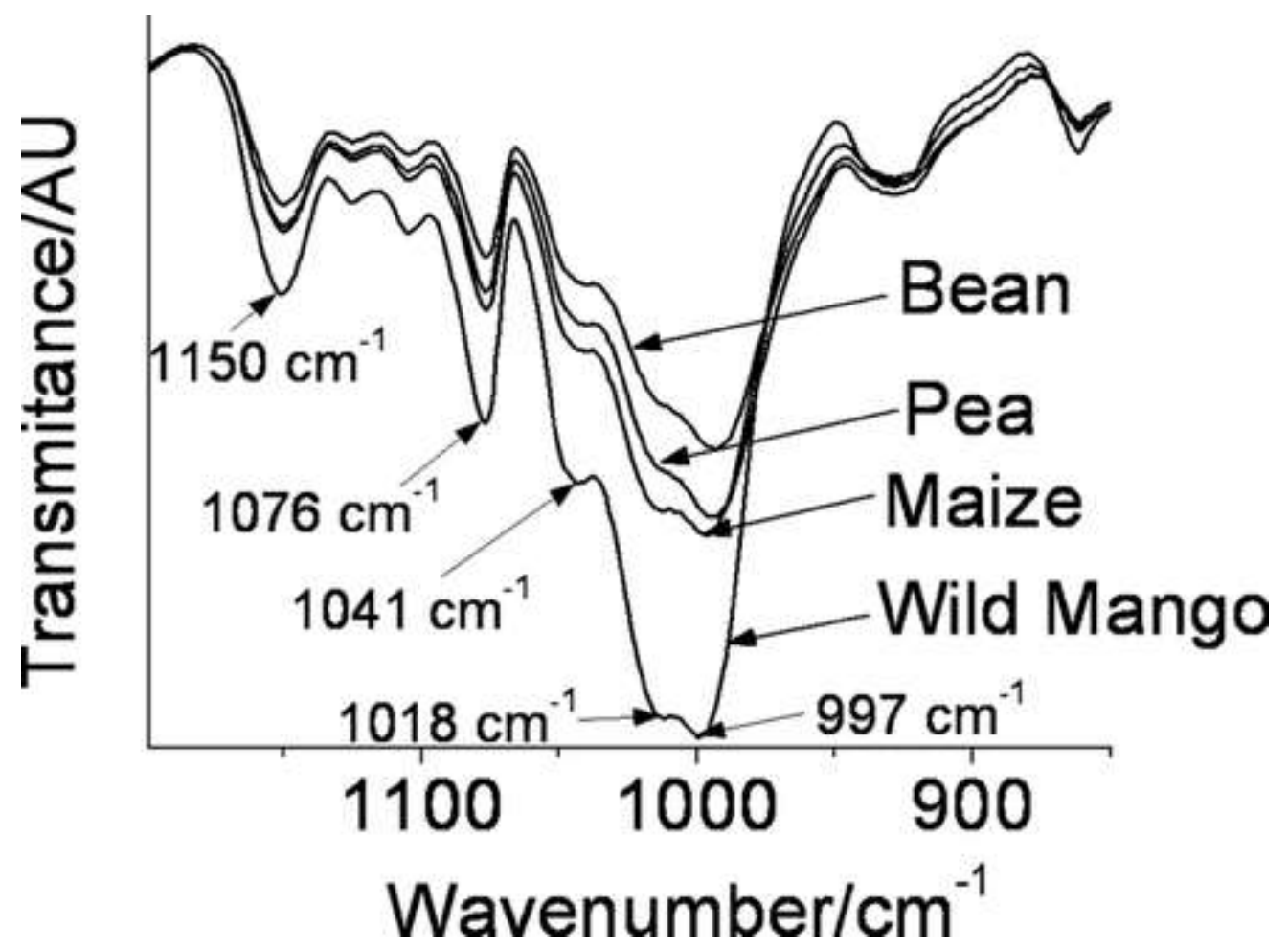

Figure 6 Fourier transform infrared spectra of wild mango starch compared to bean, pea, and maize starches. Plots are representative of three replicate measurements. All the spectra were baseline corrected, normalized, and deconvulated.

The short-range crystallinity of wild mango seed starch $(1.21 \pm 0.03)$ was significantly $(p \leq 0.05)$ higher than that of the maize $(1.12 \pm 0.01)$, pea $(1.10 \pm 0.01)$, and bean $(1.08 \pm 0.01)$ starch. This trend was in accordance with the gelatinization temperatures, which implied that the strength of the short-range intra-crystallite bonds in the amylopectin crystallites of wild mango starch was higher than that of bean, pea, and maize starch. Further research that explores relationships between the amylopectin structure and crystallinity is required to clearly understand the crystalline structure of wild mango seed starch.

\section{Conclusion}

Wild mango, although a legume, had a seed starch that is morphologically and physicochemically distinct from bean and pea starches. Its starch granules were truncated/capshaped and smaller than bean, pea, and maize starch granules. The starch had a higher crystalline order than maize and the legume starches. The pasting and cold gel properties of wild mango seed starch were more comparable to maize starch than to legume starches (bean and pea). Like other legumes, wild mango seed starch exhibited a C-type X-ray diffraction pattern. These demonstrated that wild mango offers a potential source of starch for use in product formulation as an alternative to maize, bean, and pea starch. However, given wild mango is not intensively produced like maize, peas, and beans, research needs to be conducted on: identification of suitable wild mango varieties/cultivars for starch production; scaling up of appropriate propagation and agronomic management protocols; and adoption of wild mango to new growing environments since it mainly grows in the 
eastern and southern parts of Africa. The results from such research would facilitate a more sustainable commercial utilization of wild mango starch.

\section{Novelty Statement}

The present manuscript is the first report, on the characteristics of wild mango (Cordyla africana $L$ ) seed starch. There are no known publications on the characteristics of wild mango seed starch.

\section{Acknowledgements}

The authors are grateful to Dr Sershen Naidoo (UKZN), Dr. Jai Prakash (UFS) Miss Joelle Kongolo (TUT), Ms Phindile Ndlovu and Ms Tshimangadzo Malindi (ARC) for technical assistance rendered. The authors acknowledge funding from the National Research Foundation-Grant Number 110674.

\section{Conflict of Interest}

The authors declare no conflict of interest.

\section{References}

[1] Jacobs, T., 34 Underutilized edible plants from South Africa: A perspective. Managing Plant Genetic Diversity 2001, 371.

[2] T. S. Msuya, J. R. Kideghesho, T. C. Mosha, Ecol. Food Nutr. 2010, 49, 208.

[3] S. Santacruz, K. Koch, E. Svensson, J. Ruales, A.-C. Eliasson, Carbohydr. Polym. 2002, 49, 63.

[4] C. K. Reddy, F. Luan, B. Xu, Int. J. Biol. Macromol. 2017, 105, 354.

[5] L. Copeland, J. Blazek, H. Salman, M. C. Tang, Food Hydrocolloids 2009, 23, 1527.

[6] R. F. Tester, J. Karkalas, X. Qi, J. Cereal Sci. 2004, 39, 151.

[7] R. Hoover, Crit. Rev. Food Sci. Nutr. 2010, 50, 835.

[8] L. Jayakody, R. Hoover, Carbohydr. Polym. 2008, 74, 691.

[9] I. A. Wani, D. S. Sogi, A. A. Wani, B. S. Gill, U. S. Shivhare, Int. J. Food Sci. Technol. 2010, 45, 2176.

[10] P. Ambigaipalan, R. Hoover, E. Donner, Q. Liu, S. Jaiswal, R. Chibbar, K. K. M. Nantanga, K. Seetharaman, Food Res. Int. 2011, 44, 2962.

[11] M. Joshi, P. Aldred, S. McKnight, J. F. Panozzo, S. Kasapis, R. Adhikari, B. Adhikari, Carbohydr. Polym. 2013, 92, 1484.

[12] I. M. Demiate, A. M. Figueroa, M. E. B. Z. Guidolin, T. P. R. dos Santos, H. Yangcheng, F. Chang, J. Jay-lin, Food Hydrocolloids 2016, 61, 812.

[13] AOAC, AOAC Official Method 992.23-Crude protein in cereal grains and oilseeds generic combustion method., AOAC International, Gaithersburg, MD 2005.

[14] AOAC, Official Method 920.39, AOAC International, Gaithersburg, MD 2000.

[15] N. Z. Ngobese, T. S. Workneh, B. A. Alimi, S. Tesfay, J. Food Compos. Anal. 2017, 55, 1.

[16] L. Chen, Y. Tian, Y. Bai, J. Wang, A. Jiao, Z. Jin, Food Hydrocolloids 2017, 77, 85.

[17] J. I. Kongolo, L. S. Da Silva, O. C. Wokadala, B. Du Plessis, J. Husselman, M. E. K. Ngcobo, N. M. Emmambux, M. S. Daneel, J. Food Meas. Charact. 2017, 11, 1056. 
[18] S. Wang, Y. Sun, J. Wang, S. Wang, L. Copeland, Food Funct. 2016, 7, 1188.

[19] R. Hoover, T. Hughes, H. Chung, Q. Liu, Food Res. Int. 2010, 43, 399.

[20] M. G. Cappai, G. A. Alesso, G. Nieddu, M. Sanna, W. Pinna, Food Funct. 2013, 4, 917.

[21] V. Vamadevan, E. Bertoft, Starch/Stärke 2015, 67, 55.

[22] J. Liu, X. Wang, F. Wen, S. Zhang, R. Shen, W. Jiang, J. Kan, C. Jin, Int. J. Biol Macromol. 2016, 93, 107.

[23] F. Zhu, Carbohydr. Polym. 2015, 122, 456.

[24] B. Zhang, J.-Q. Mei, B. Chen, H.-Q. Chen, Food Chem. 2017, 229, 136.

[25] M. S. Madruga, F. S. M. de Albuquerque, I. R. A. Silva, D. S. do Amaral, M. Magnani, V. Q. Neto, Food Chem. 2014, 143, 440.

[26] J. Chen, Y. Liang, X. Li, L. Chen, F. Xie, Carbohydr. Polym. 2016, 150, 269.

[27] V. Tulyathan, K. Tananuwong, P. Songjinda, N. Jaiboon, ScienceAsia 2002, 28, 37.

[28] O. A. Odeku, Starch/Stärke 2013, 65, 89.

[29] F. B. Ahmad, P. A. Williams, J.-L. Doublier, S. Durand, A. Buleon, Carbohydrate polym. 1999, 38, 361.

[30] E. Malinski, J. R. Daniel, X. X. Zhang, R. L. Whistler, Cereal Chem. 2003, 80, 1.

[31] J. Jane, Y. Chen, L. Lee, A. McPherson, K. S. Wong, M. Radosavljevic, T. Kasemsuwan, Cereal Chem. 1999, 76, 629.

[32] S. Li, Y. Zhang, Y. Wei, W. Zhang, B. Zhang, J. Bioprocess. Biotech. 2014, 4, 161.

[33] Z.-H. Lu, E. Donner, R. Y. Yada, Q. Liu, Food Chem. 2012, 133, 1214.

[34] R. Raghunathan, R. Hoover, R. Waduge, Q. Liu, T. D. Warkentin, Food Chem. 2017, 221, 1514.

[35] H. Zobel, Starch/Stärke 1988, 40, 44.

[36] J. Van Soest, D. De Wit, H. Tournois, J. Vliegenthart, Polymer 1994, 35, 4722. 